\section{Commentary: Zone 0 thoracic endovascular aortic repair stroke risk remains too high}

\author{
Alexander A. Brescia, MD, MSc, and \\ Shinichi Fukuhara, MD
}

Kudo and colleagues ${ }^{1}$ report mid-term results after zone 0 thoracic endovascular aortic repair (TEVAR) using the Bolton (Bolton Medical, Inc, Sunrise, Fla) branched endograft at their center between 2012 and 2018 in patients with degenerative thoracic aneurysm $(22 / 28,79 \%)$ or dissection $(6 / 28,21 \%)$. This study represents the largest series using the dual branched device system with relatively long follow-up data. In this context, the authors must be congratulated.

At a mean follow-up of 4 years, the authors report procedural success in all patients and an $81 \%$ 5-year survival but a $14 \%(4 / 28)$ perioperative stroke rate. ${ }^{1}$ The authors conclude that using this branched stent graft for zone 0 TAVR may provide a less-invasive treatment compared with open and hybrid approaches.

The authors indicate that a fully endovascular approach using branched stent grafts provides a less-invasive alternative to hybrid approaches using an aortocervical bypass and TEVAR. However, the technique described here still requires an extra-anatomical axillary-axillary or axillarycarotid bypass procedure in conjunction with TEVAR. In addition, a technique with a perioperative stroke rate of $14 \%$ will not be found to be an acceptable or sustainable solution for the aortic community. Interestingly, all 4 patients who suffered perioperative stroke had a grade 2 or greater atheroma in the innominate artery, highlighting that these

From the Department of Cardiac Surgery, University of Michigan, Ann Arbor, Mich. Disclosures: The authors reported no conflicts of interest.

The Journal policy requires editors and reviewers to disclose conflicts of interest and to decline handling or reviewing manuscripts for which they may have a conflict of interest. The editors and reviewers of this article have no conflicts of interest.

Received for publication Nov 16, 2020 ; revisions received Nov 16, 2020; accepted for publication Nov 26, 2020; available ahead of print Dec 5, 2020.

Address for reprints: Shinichi Fukuhara, MD, Department of Cardiac Surgery, University of Michigan, 1500 E Medical Center Dr, Ann Arbor, MI 48109 (E-mail: fukuhara@med.umich.edu).

JTCVS Techniques 2021;5:12

2666-2507

Copyright $(2020$ The Authors. Published by Elsevier Inc. on behalf of The American Association for Thoracic Surgery. This is an open access article under the CC BY-NCND license (http://creativecommons.org/licenses/by-nc-nd/4.0/).

https://doi.org/10.1016/j.xjtc.2020.11.029

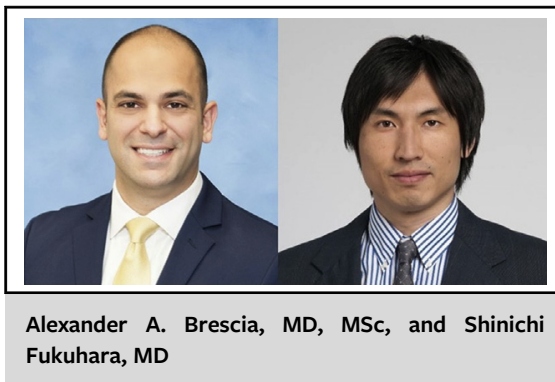

CENTRAL MESSAGE

Zone o thoracic endovascular aortic repair techniques offer a less-invasive alternative to open or hybrid repair but should be used with caution due to an increased risk of perioperative stroke.

patients should be identified preoperatively to undergo open repair or that intraoperative stroke prevention techniques must be improved.

While the authors should be commended on avoiding any perioperative mortalities, a fully endovascular zone 0 approach should be used with caution, given the high rate of perioperative stroke found here, as well as in previous series of hybrid and completely endovascular approaches. ${ }^{2,3}$ We feel the advantages gained by avoiding sternotomy and circulatory arrest may be overshadowed by an increased risk of perioperative stroke. Lastly, we must remember, an extra-anatomic bypass procedure alone is not a trivial procedure, including the risks of stroke, recurrent laryngeal, and phrenic nerve injuries. ${ }^{4}$ As a result, until improvements are made in mitigating stroke risk, zone 0 TEVAR should still be reserved for patients at absolute prohibitive risk for open repair.

\section{References}

1. Kudo T, Kuratani T, Shimamura K, Sawa Y. Early and midterm results of thoracic endovascular aortic repair using a branched endograft for aortic arch pathologies: a retrospective single-center study. J Thorac Cardiovasc Surg Tech. 2020;4:17-25.

2. Preventza O, Tan CW, Orozco-Sevilla V, Euhus CJ, Coselli JS. Zone zero hybrid arch exclusion versus open total arch replacement. Ann Cardiothorac Surg. 2018; 7:372-9.

3. van Bakel TM, de Beaufort HW, Trimarchi S, Marrocco-Trischitta MM, Bismuth J, Moll FL, et al. Status of branched endovascular aortic arch repair. Ann Cardiothorac Surg. 2018;7:406-13.

4. Voigt SL, Bishawi M, Ranney D, Yerokun B, McCann RL, Hughes GC. Outcomes of carotid-subclavian bypass performed in the setting of thoracic endovascular aortic repair. J Vasc Surg. 2019;69:701-9. 